\title{
THE GOAL-ORIENTED APPROACH TO EVALUATION: CRITIQUE AND CASE STUDY FROM DRUG ABUSE TREATMENT
}

\author{
JEANNÈ C. MaRsh \\ Institute for Social Research \\ University of Michigan
}

\begin{abstract}
The specification and measurement of program goals remains central to most evaluation research strategies, yet procedures for implementing this approach are not well-articulated. It is the purpose of this discussion to describe a stepwise procedure for programmatic goal setting and monitoring used in a demonstration drug treatment program for women. Three implementation steps are described: (a) goal setting, (b) checking for consistency, (c) monitoring and feedback. The advantages and limitations of this approach are discussed and useful complementary measurement strategies are suggested.
\end{abstract}

\section{INTRODUCTION}

The specification and measurement of program goals is central to most evaluation research strategies described in the literature (Riecken, Boruch, Campbell, Caplan, Glennan, Pratt, Rees, Williams, 1974; Suchman, 1967; Tripodi, Fellin and Epstein, 1971; Weiss, 1972). The nature of an evaluative study is such that it must document what a program does and then determine what effect it has. The failure to specify the focus and level of an intervention can lead to the measurement of irrelevant variables and the generation of misleading results (Charters and Jones, 1973; Rossi, 1972). While the documentation of the focus and impact of program implementation can be accomplished in a variety of ways, the specification and measurement of program goals provides perhaps the most frequently articulated approach. Despite general agreement on the role of goal setting and measurement in evaluation research, the task is complex and its dimensions are not well-defined.

The inadequate understanding of most social problems as well as the minimal knowledge of effective ameliorative strategies makes the task of defining and operationalizing goals difficult for even the most competent program staff and researchers. For some social programs the nature of the problem and the intervention are such that goal setting proves less problematic. Programs such as population control programs have a well-defined intervention, the provision of birth control education and devices, and an objective outcome measure, population growth. Many social problems, however, are concerned with less clear-cut problems, e.g., treatment and prevention of mental illness, delinquency control and prevention, or substance abuse prevention and control. Each of these phenomena are open to numerous definitions. And the targets for intervention for these problems are likely to be equally diverse.

The goal setting task is further complicated by the fact that as programs mature, needs for evaluative information change. For new programs, when major attention must be given to establishing new modes of service delivery, a focus on process objectives is needed to determine if services are being provided as intended. Later, when service strategies are established, studies of whether and under what conditions services are having the desired impact on clients becomes important. Eventually, an evaluation of the impact of the program on other organizations and on the community is relevant. Tripodi, Fellin and Epstein (1971) emphasize the importance of tailoring program goals to the various stages of program development and call this approach differential evaluation. They suggest the analysis of the effects of the program intervention are premature and unproductive in the early stages of program development. The achievement of goals related to the ultimate outcome of the program is often dependent on the success with which problems of program implementation have been managed. 


\section{SPECIFICATION AND MEASUREMENT}

The specification and measurement of program goals is central to evaluation research strategies which focus on the assessment of social programs (Suchman, 1967; Weiss, 1972; Riecken, Boruch, Campbell, Caplan, Glennan, Pratt, Rees, Williams, 1974). However, goal setting and monitoring has been found to be useful in other efforts as well. For some time, social psychologists have documented the strong relationship of motivation to goals and of the impact of individual goals on outcomes for both the individual and the group (Atkinson, 1968; Zander, 1971). Mental health professionals have capitalized on the efficiency of goal-directed behavior and have incorporated goal setting and monitoring into treatment approaches to enhance therapeutic gain and to aid the evaluation of treatment outcome (Bandura, 1969; Kiresuk and Sherman, 1968; Houts and Scott, 1972; Reid and Epstein, 1972). Kiresuk and Sherman's Goal Attainment Scaling is perhaps the most widely disseminated of the goal-oriented approaches to the evaluation of individual treatment effectiveness which have been developed in recent years (Mager, 1972; Davis, 1973; Miller 1973; Bolin and Kivens, 1974). The identification of goals and values is also an important component of the multiattribute utility analysis developed by Guttentag, Edwards and Snapper (1975) to aid decision-making of federal level policy makers. In business, goal setting and monitoring is central to at least one approach to contemporary management practice. The MBO (Management by Objectives) system represents a widely distributed example of this approach (Raia, 1974).

While goal-oriented approaches to treatment, evalua- tion, decision-making and management practice have proliferated, few descriptions of these approaches contain specific information to guide the evaluation researcher seeking to establish and measure program goals. It is the purpose of this discussion to present an explicit procedure for programmatic goal setting and monitoring which was used in a demonstration drug treatment program for women. A discussion of the advantages and limitations of the procedure specifically as well as the goal-oriented evaluation in general will follow.

The implementation of goal-oriented evaluation in a drug treatment program provides a particularly informative test of this method. Effective strategies for the treatment of heroin addiction have not been determined. Appropriate treatment methods for heroin addicted women, in particular, remain unidentified (Doyle and Levy, 1975; Rosenthal, Spillane and Greene, 1976). Thus, the discussion will describe the use of goal-oriented evaluation in a program with minimal information as to appropriate direction and focus. Furthermore, the paper will describe the use of a goal-oriented method in the early stages of program development when goals focus on process, i.e., on the tasks required for organizational development: securing resources, developing treatment technology, facilitating staff skill development, coordinating activites within the program. Except for changes in the content of goals, the goal setting and monitoring procedure remains essentially constant throughout the life of the program. The present discussion will focus on and present data from the implementation period when goal-oriented evaluation methods were introduced to the program staff.

\section{PROGRAM DESCRIPTION}

The WOMAN (Women Organized to Move Against Narcotics) Center is a community-based methadone maintenance program for heroin-addicted women in Detroit. A grass-roots effort, the program was conceptualized and designed by a group of women in the Cass Corridor who felt women addicts in their neighborhood were not receiving adequate treatment in traditional methadone maintenance programs. So the program was broadly defined to "meet the unique needs of women" and included an all-female staff and a child care center. The originators of the program took positions on the Board of Directors and they hired women, the majority of whom were paraprofessionals from the neighborhood, as program staff. The characteristics of the program that are particularly relevant to this discussion are (1) that it was a newlydeveloped program and (2) that the staff were relatively inexperienced in program development and evaluation.

\section{PROCEDURE FOR GOAL SETTING AND MONITORING}

There are three aspects of goal setting and monitoring as implemented at the WOMAN Center. The first involves providing program staff with a rationale and instructions describing the purpose as well as techniques for setting objective, measureable program goals. The second step involves assessing goals the program identifies for consistency with objectives of the program as set forth by other groups or individuals with investment in the program, e.g., program founders, a Board of Directors, or a funding source. The final step involves goal monitoring and feedback for purposes of program planning and development. These steps are summarized in the diagram in Figure 1 and described below.

\section{Step 1. Goal setting}

Staff members who have not previously been involved in an evaluation effort are likely to be unfamiliar with the relevance of clearly specified program goals for program planning and development as well as for a meaningful evaluation. For example, the majority of the WOMAN Center staff had no previous experience in the development and evaluation of a treatment program, and they had not considered the usefulness of clearly defined goals for the program or for the evaluation. Initially, the evaluation staff may have to educate program staff regarding the importance of translating treatment procedures and intended effects into researchable terms and provide 


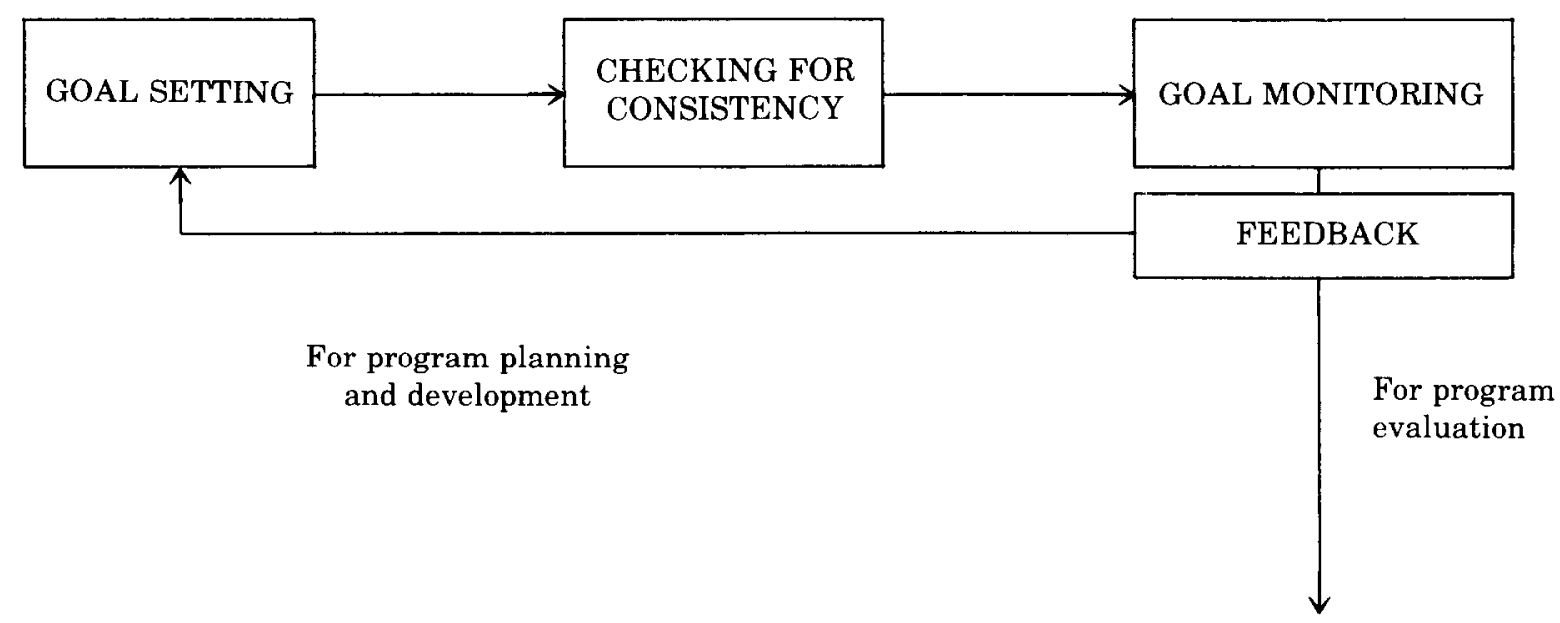

Figure 1. Goal setting and monitoring steps.

them with techniques for doing so. Frequently, the best strategy requires that staff become involved in setting program goals immediately and acquire insight into the importance of goal setting for the evaluation as a function of this activity. Evaluation staff can provide one or two rules to program staff to guide them in their goal setting efforts and then work with them to identify actual program goals and to translate them into researchable terms.

In order for all aspects of the program to be represented in the goals, all program staff (or representatives of program staff) including administrators, treatment and support staff should be involved in the goal setting process. Within a given program, administrators and treatment staff are likely to be concerned with different aspects of the program (Etzioni, 1960). Intervention staff are, of course, concerned with the delivery of service while administrative staff must be concerned with the maintenance of the program, recruitment of additional resources and the relationship of the program to outside forces funding sources, other agencies and community groups. Thus, depending on position within the organization, program staff are likely to be concerned with different types of goals. By involving staff from all aspects of the program, goals are likely to be more representative of the total program. Indeed, at the WOMAN Center, each component of the program developed individual component goals which were then incorporated into the total program goals.

A number of factors contribute to the difficulty of this task. First, particularly in a new program, there is likely to exist a lack of consensus regarding the most important independent and dependent variables. Additionally, the divergent values and orientations of treatment and evaluation staff are likely to become obvious as a result of this process. Treatment staff conceptualize the treatment program in terms of multiple independent and dependent variables. Evaluation researchers, on the other hand, seek less complex relationships and would like the program staff to sort out the most critical and relevant variables for measurement. Treatment staff are primarily concerned with the efficient delivery of best available service. Evaluation researchers seek to determine what is the best, or most effective service. These conflicting orien- tations are inherent in the evaluation task, and to the extent that they can be acknowledged and anticipated, their impact can be minimized.

The acceptability of the goal setting procedure to program staff will be enhanced to the extent that it is perceived as an aid to program planning and development as well as an evaluation tool. Goal setting can be described as a useful means for delineating the focus and direction of a new program. For example, it was pointed out to WOMAN Center staff that as part of the initial goal setting process, various staff members' conceptualizations of the purpose and function of the program could be negotiated until a consensus emerged in the form of program goals. Additionally at this time, the frequency and format of goal achievement feedback was discussed so that evidence of regular and tangible outcome of staff efforts was apparent.

\section{Step 2. Checking for consistency}

Once program goals have been written, it is necessary to determine their consistency with expectations of other groups or individuals having interest or investment in the program. These groups can include initiators of program proposals, a funding source, a Board of Directors, a licensing agency. This phase is useful for a number of reasons. In cases where federal or regional directives exist, this comparison provides a clear picture of whether or not these directives are being met. In other cases where program expectations are prescribed by groups such as an advisory board, a licensing or funding source, this consistency check determines the degree to which the program goals parallel or diverge from the expectations of these groups. The consistency check provides an opportunity for identifying discrepancies and obtaining consensus when this is appropriate.

In many cases, the expectations of outside groups have not been committed to paper. In such cases verbal approval of program goals by outside groups may be the appropriate strategy. In cases where expectations are written in some form (i.e., the funding proposal, licensing agency directives, a Board of Directors philosophy statement), it is useful to formally match program goals with directives or statements of philosophy. A more formal 
strategy is particularly useful when written expectations are available from more than one unit. For example, expectations from all units can be placed on one axis of a matrix. Program goals can then be placed on the other axis so that goals and expectations can be systematically matched. This procedure makes it possible to determine graphically that at least one goal statement addresses every set of expectations. This procedure was used at the WOMAN Center to relate program goals to the philosophy statements set forth by the Board of Directors. A subset of goals and philosophy statements appear in Figure 2.
As is apparent from Figure 2, expectations from different units can be overlapping, but they should not be contradictory. When it is impossible for the program to logically fulfill contradictory expectations from two sources, the program must negotiate with one or the other unit to resolve this constraint. This step was particularly valuable at the WOMAN Center where program founders remained involved on the Board of Directors. These individuals had a strong investment in the program and definite expectations about appropriate program goals that were not totally consistent with the expectations of the program staff. These inconsistencies were clarified and

Figure 2.

\section{CONSISTENCY MATRIX}

\begin{tabular}{|c|c|c|c|}
\hline GOALS & $\begin{array}{l}\text { Develop quality program } \\
\text { with funded \& voluntary } \\
\text { staff to assist women with } \\
\text { mental, physical or en- } \\
\text { vironmental problems. }\end{array}$ & $\begin{array}{l}\text { Provide a mechanism for col- } \\
\text { lecting \& sharing informa- } \\
\text { tion, resources \& skills to } \\
\text { help women with survival } \\
\text { problems. }\end{array}$ & $\begin{array}{l}\text { Develop relationship with } \\
\text { other org. \& groups that deal } \\
\text { with issues affecting wo- } \\
\text { mens' lives. }\end{array}$ \\
\hline $\begin{array}{l}\text { 1. The Community Resource Coordinator } \\
\text { will maintain a current and up-to-date } \\
\text { log of community organizations, agencies } \\
\& \text { institutions which may be useful to } \\
\text { WOMAN Center. This log will: } \\
\text { a. be systematized by } 2 / 15 / 76 \text {, } \\
\text { b. be updated monthly, } \\
\text { c. include name, services, location, con- } \\
\text { tact person \& notes regarding contacts } \\
\text { with WOMAN program. }\end{array}$ & & $\mathrm{x}$ & $\mathrm{x}$ \\
\hline $\begin{array}{l}\text { 2. The Community Resource Coordinator } \\
\text { will meet weekly with community aides } \\
\text { to share resources, problems \& to com- } \\
\text { municate recruitment efforts. }\end{array}$ & & $\mathrm{x}$ & \\
\hline $\begin{array}{l}\text { 3. Team Coordinators will develop an audit } \\
\text { sheet for WOMAN members which will } \\
\text { reflect the member's progress through } \\
\text { the program \& dates on which each step } \\
\text { in the process is completed including: } \\
\text { a. completion of intake process, } \\
\text { b. completion of orientation process, } \\
\text { c. assignment of counselor, } \\
\text { d. development of treatment plan, } \\
\text { e. methadone dosage when appropriate. }\end{array}$ & $\mathrm{x}$ & & \\
\hline $\begin{array}{l}\text { 4. The Treatment Coordinator will review } \\
\text { all treatment plans on a quarterly basis. }\end{array}$ & $\mathrm{x}$ & & \\
\hline $\begin{array}{l}\text { 5. Individual counseling sessions will be } \\
\text { held with children in the program on a } \\
\text { weekly hasis. }\end{array}$ & $\mathrm{x}$ & & \\
\hline $\begin{array}{l}\text { 6. The Program Director will assign each } \\
\text { treatment staff person an area of advo- } \\
\text { cacy. }\end{array}$ & $\mathrm{x}$ & $\mathrm{x}$ & \\
\hline
\end{tabular}


reduced early in the program development as a result of this step in the goal setting process.

\section{Step 3. Monitoring and feedback}

Once program goals have been developed, a procedure must be established for monitoring achievement of goals. Then this information must be provided to the program in a form that can be used readily for program planning and development as well as for evaluation purposes. The evaluation staff must derive a data collection system that allows for accurate, efficient summary of these data both for purposes of the program and the evaluation. Since these data are basically qualitative (i.e., descriptions of levels of goal achievement), this can consist of an evaluation staff member who uses methods of naturalistic observation to document goal achievement. Some evaluators have attempted to make this a more quantitative procedure by assigning numbers to levels of goal achievement and weightings to various goals so that a goal achievement score can be calculated. In some cases, interval level statistics have been applied to test for post-treatment differences (Kiresuk and Sherman, 1968). Other evaluators who have rated levels of goal achievement, simply placed levels of achievement on graphs and updated the graphs monthly (Austin, 1974). Selection of a

Figure 3.

FEEDBACK FORMAT FOR SELECTED SUBSAMPLE OF WOMAN CENTER GOALS PHILOSOPHY STATEMENTS

\begin{tabular}{l} 
GOAL \\
\hline 1. The Community Resource Coordinator \\
will maintain a current and up-to-date \\
log of community organizations, agencies \\
and institutions for use of WOMAN \\
Center. This log will: \\
a. be systematized by $2 / 15 / 76$, \\
b. be updated monthly, \\
c. include name, services, location, con \\
tact person \& notes regarding contacts \\
with WOMAN program
\end{tabular}

2. The Community Resource Coordinator will meet weekly with community aides to share resources, problems \& to communicate recruitment efforts.

3. Team Coordinators will develop an audit sheet for WOMAN members which will reflect the members' progress through the program \& dates on which each step in the process is completed including:

a. completion of intake process,

b. completion of orientation process,

c. assignment of counselor,

d. development of treatment plan,

e. methadone dosage when appropriate.

4. The Treatment Coordinator will review all treatment plans on a quarterly hasis.

5. Individual counseling sessions will be held with children in the program on a weekly basis.

6. The Program Director will assign each treatment staff person an area of advocacy.

\begin{tabular}{|c|c|c|}
\hline $\begin{array}{c}\text { REVIEW DUE } \\
\text { DATE }\end{array}$ & $\begin{array}{c}\text { GOAL } \\
\text { STATUS }\end{array}$ & COMMENTS \\
\hline $\begin{array}{l}2 / 15 / 76 \\
\text { and monthly }\end{array}$ & Met & $\begin{array}{l}\text { This } \log \text { has been developed, incorporates } \\
\text { the stated information and is up-dated as } \\
\text { new information hecomes available. }\end{array}$ \\
\hline $2 / 29 / 76$ & Met & \\
\hline $2 / 2 / 76$ & Met & \\
\hline Quarterly & $\begin{array}{c}\text { Partially } \\
\text { met }\end{array}$ & $\begin{array}{l}\text { The individual counselors attempt to meet } \\
\text { this goal but have not been totally success- } \\
\text { ful. }\end{array}$ \\
\hline $2 / 1 / 76$ & Not met & $\begin{array}{l}\text { Reduction in the number of Child Care staff } \\
\text { rendered this goal impossible. }\end{array}$ \\
\hline $2 / 2 / 76$ & Met & $\begin{array}{l}\text { The advocacy areas include: education, } \\
\text { employment, food resources, legal, dental, } \\
\text { medical, housing, mental health \& social } \\
\text { service assistance. Some advocates handle } \\
\text { more than one area of advocacy. }\end{array}$ \\
\hline
\end{tabular}


monitoring and feedback system depends on how the information will be used. If the information is collected only to derive a goal attainment or change score, then quantitative procedures are appropriate. If, however, these methods are designed to aid in program planning and decision-making, more qualitative information is necessary.

The WOMAN Center used naturalistic observation to monitor goal achievement and then provided feedback in the form of tables which included a rating of goal achievement. These ratings were on a simple three point scale: met, partially met, not met. The ratings were made by a member of the evaluation staff working on-site at the WOMAN Center who observed program functioning with special attention to goal-related activities. In addition to direct observation, other data sources, such as memos, minutes from meetings, client folders, were used to derive information upon which ratings were based. Feedback to the WOMAN Center also included subjective comments on possible implications of achievement or nonachievement. (See Figure 3 for a sample feedback format.)

Feedback on all goals was provided at six month intervals during the first two years of program functioning. The WOMAN Center staff used the feedback as a corrective device in program planning and development. The information appeared to be particularly useful for staff and resource allocation. Upon receipt of the feedback, program staff began modifying old goals and setting new ones. The simple ratings provided a clear indication of (1) areas in which goals had been met allowing the program to progress to the next logical set of goals; (2) areas where goals were not met and required additional resources (or a more realistic assessment of the feasibility of goals given present resources); or (3) areas where goals were only partially met and would require continued attention. Comments from the evaluator were most frequently provided for goals which were not met or only partially met. The comments typically described the evaluator's assessment of the reasons goals were not achieved. This information was designed to aid the program in their decision to pursue a goal, perhaps with more resources and more time, or to drop an unrealistic or inappropriate goal. For evaluation purposes, the biannual feedback was useful for gauging program development and determining the adequacy and appropriateness of outcome measures.

The goal setting and monitoring procedure utilized at the WOMAN Center represents the specification of a goal-oriented evaluation approach. Inherent in this general approach are certain strengths and limitations evaluation researchers must be aware of when utilizing the approach.

\section{ADVANTAGES OF THE GOAL-ORIENTED APPROACH}

\section{Goals may be tailored to stages of program de- velopment}

Although the determination of program goals is not an easy task, the consistency between program goals and program outcome has been established as a basic measure of effectiveness in program evaluation. Furthermore, the goal-oriented approach permits differential evaluation, i.e., definitions of effectiveness to change as the program or organization progresses through various stages of development. As a program develops, it becomes more important to measure goals related to the impact of the service innovation on the clients. The evaluation of process goals is designed to provide information for improving the program. A good process evaluation allows the program to reorganize and improve so that it will make a better showing on the evaluation of outcome.

Program determined goals reduce influence of evaluator bias

Goal-oriented evaluation represents an objective and reliable approach because it uses goals established by the program as criteria for judgment. The beliefs and values of the evaluator are less likely to influence the study since the effectiveness of the program is determined by its capacity to achieve those objectives identified as important by the program staff. And because this approach identifies effectiveness measures that are idiosyncratic to the program, it affords flexibility that makes it useful in a variety of settings.

\section{Goal setting has beneficial by-products for the pro- gram}

In addition to its usefulness for evaluation, there are by-products of the goal-oriented approach that are beneficial to the program. The process of selecting certain expectations as program goals accomplishes two things. First selecting a subset of goals out of all thuse pussible serves to clarify program purpose and function. Particularly in new and innovative programs, there may be disagreements or misconceptions regarding the purpose of the program. The process of selecting certain goals and committing them to paper requires some consensus be achieved among relevant groups. Second, by establishing certain expectations for itself the program can assess program activities in terms of these expectations and make changes and modifications in order to meet goals. In this way the goal-oriented approach capitalizes on the self-fulfilling prophesy phenomenon or what has been described in the context of evaluation research as "target tropism" (Davis, 1974). It is obvious that the careful clarification of a goal is a necessary, and at times sufficient, step for achieving the goal.

\section{Goal setting may be incorporated into program functioning}

An additional advantage of the goal-oriented approach is that straight-forward procedures can be developed and incorporated into ongoing program functioning. It is clear from the use of programmatic goal setting at the WOMAN 
Center that while goal setting and monitoring requires staff time and effort, and in some cases, negotiation in the selection of goals, the ability to select goals and to write them in researchable terms is a skill that can be de- veloped readily requiring only instruction and practice. And once program staff have acquired the skill, it can be usefully applied to program planning and development as well as to evaluation tasks.

\section{LIMITATIONS OF THE APPROACH}

In addition to the positive aspects of this evaluative approach, there are some limitations that must be considered in its application. For example, it has been suggested that a goal-oriented approach promotes a "biased" evaluation in the sense that certain outcomes are identified for measurement while others arc ignored. Understanding that all methods introduce bias, it is important to recognize the particular sources of bias accompanying the use of goal-oriented evaluation.

\section{Stated goals may not be real goals}

First, despite the fact that a goal-oriented model utilizes program-generated criteria for the assessment of effectiveness, the goals it claims to pursue may not be those it actually follows. If the formal goals are very different from the informal goals, information derived from their evaluation can be misleading. Some evaluation researchers claim formal goals as real goals of the organization; others choose them because they are easier to determine (Etzioni, 1960). It remains, however, that if program activities are extremely different from what program staff say they are trying to do, the information derived from a goal-oriented evaluation will be of little value.

\section{Unintended outcomes may be ignored}

A second source of bias in the goal-oriented procedure results from the possibility that other valid but unintended program outcomes will be ignored. Identification of program goals creates expectations. This increases the possibility that change will be seen in the identified arcas and decreases the possibility that it will be found otherwise. A clear example of this occurred in the WOMAN Center. Program goals were specified and agreed upon by all components of the program including administrators, treatment staff and support staff. All of these goals related to the treatment and prevention of heroin addiction among women. However, it became increasingly apparent to evaluators that - most likely because the facility is called the WOMAN Center (a name which in no way indicates that it is a facility designed to meet only the needs of drug-addicted women) - the receptionist received a number of calls for information related to needs of women other than drug-addicted women. She spent some portion of her time and resources each day providing information and making referrals to, among other things, feminist financial institutions, rape crisis centers and abortion clinics. This activity was not related to any of the stated goals. The fact that it was accepted as legitimate by all program staff suggests that the organization was pursuing goals in addition to those described for purposes of evaluation of the drug treatment program. The description of program goals limited to the treatment of heroinaddicted women led the evaluation to describe program outcomes for heroin-addicted women and to miss outcomes which indicated this facility was meeting needs of a broader population of women in the community. In this particular case where the treatment facility intends to seek additional funding from non-drug-related agencies, some documentation of non-drug-related efforts could have been useful. An alternative evaluation strategy designed to avoid this particular source of bias is goal-frec evaluation explicated initially by Michael Scriven (Salasin, 1974). In a goal-free evaluation, knowledge of program goals is avoided in the determination of program effectiveness. The goal-free approach is based on the notion that there is no need to know goals in order to assess program outcomes. According to Scriven, a goal-free evaluation is designed to evaluate what a program actually does rather than what is trying to do. The procedure followed by a goal-free evaluator involves avoiding direct contact with the program staff as well as avoiding discussions about program history or program goals (i.e., information that would influence his determination of program effectiveness). Instead, the evaluator attempts to observe those program inputs and outcomes that appear significant. The goal-free evaluator identifies the goals of the program to the extent that they are expressed in observable treatment efforts and outcome.

Although the WOMAN Center evaluation has not incorporated the methods prescribed by Scriven, the evaluation has attempted to include a number of different outcome measures relevant for drug treatment of women in addition to those suggested by the program goals.

\section{Possibility of cross-program comparison may be limited}

Many evaluation efforts are designed to compare the effectiveness of one program with another. In some cases it may be possible to standardize at least some program goals. To the extent that standardized goals are relevant to the programs to be compared, it may be possible to determine program effectiveness in terms of the achievement of these goals. However, to the extent that different programs with ostensibly the same purpose identify slightly different or idiosyncratic outcome goals, a goaloriented approach is limited in its usefulness for crossprogram comparison.

\section{Effects of organization may not be measured}

Social programs are multifunctional organizations. In addition to the stated or real goals of the organization, some time and resources must be devoted to non-goal functions such as recruiting personnel and resources to perform goal activities, maintaining resources and facilities, facilitating social integration of staff. All such activities - as well as goal-oriented activities - are functional and increase organizational effectiveness. Indeed, an organization that devotes all its efforts to fulfilling one functional requirement, even if it is that of performing goal activities, will undermine even this activity, 
because activities such as recruitment of means, maintenance of facilities and the social integration of staff will be neglected. Implications for a goal-oriented evaluation are that this model fails to measure large segments of organizational activity that are not identified in terms of program goals. To the extent that program goals are determined by staff of diverse program components, and an effort is made to include process and outcome program goals, a broader representation of goals can be achieved. Nevertheless, without additional measurement, many program dynamics contributing to goal achievement are lost.

In response to this limitation of the goal-oriented model, a systems model of organizational analysis has been suggested (Etzioni, 1960; Schulberg and Baker, 1968). Such a model assesses the allocation of organizational resources rather than goals to determine the effectiveness of program functioning. Although this model has been applied in a number of settings, procedures for its use are not yet well-developed. However, the literature describing strategies for organizational analysis and change is developing rapidly. And the assessment of the structure and function of the organization can provide useful information for program evaluation - if only for the interpretation of goal achievement or lack of achievement.

To address the inattention to organizational considera tions of a goal-oriented approach, the WOMAN Center evaluation includes an organizational analysis which attempts to describe the formal and informal structure of the organization, the sources of power, the decisionmaking process, staff satisfaction and dissatisfaction (Hluchyj, 1976). These data provide a rich source of information for interpreting and understanding program progress and impact.

\section{SUMMARY}

A discussion of a goal-oriented approach to program evaluation based on the use of this method in a druy treatment program for women indicates this to be a valuable approach for several reasons. The goal-oriented method limits influence of evaluator bias by using program identified goals as criteria for measurement. Further, the goal-oriented method has great flexibility that allows for its use in conjunction with human service programs progressing through various stages of development. Its use has important programmatic benefits in the sense that it forces programs to specify goals which, of course, increases the possibility they will achieve these goals. Whether a goal-oriented strategy is used on the level of individual treatment evaluations or as a program evaluation strategy, the specification of goals is recognized as a necessary, and at times sufficient, step for goal achievement. Finally, goal-oriented evaluation can be implemented with staff who have minimal experience or sophistication with respect to evaluation.

The limitations or sources of bias that accompany this model derive from the fact that the specification of program goals (1) is useful only to the extent that the most important or representative goals are selected for measurement, and (2) increases the possibility that evaluators will miss or ignore unspecified or unintended program effects. Further, when programs with the same purpose specify slightly different outcome goals, the goal-oriented approach is restricted in its usefulness for cross-program comparisons. One last limitation of the goal-oriented approach rests in its failure to account for the organizational structure and function that ultimately contributes to the achievement of program goals.

\section{CONCLUSIONS}

There are several implications for the evaluation endeavor that emerge from this critique of the goal-oriented approach. First, information critical for the assessment of program function and outcome, i.e., what a program is trying to do and how it is trying to do it, can be obtained through program goal setting and monitoring. Further, information that is obtained is useful for program planning and development as well as for program evaluation. And the procedure for obtaining the information is straightforward and can be readily incorporated into program activities. However, the evaluation researcher who elects to use a goal-oriented evaluation strategy must be aware of the limitations or biases introduced by this method. Specifically, this approach may lead the researcher to neglect informal organizational goals, unintended outcomes, or organizational dynamics that influence the achievement of program goals. With knowledge of these biases an informed decision can be made to supplement a goal-oriented approach with appropriate additional measurement strategies. Depending on the purpose of the evaluation effort, goal-free strategies as well as organizational analytic strategies have been identified as particularly relevant for use in conjunction with a goal-oriented evaluation. 


\section{REFERENCES}

AtKinson, John W. Motives in Fantasy, Action and Society. New York: Van Nostrand Co., 1958.

Austin, Nancy. The use of goal attainment scaling in community mental health: Training and implementation. In Geoffrey Garwick and Joan Brintnall (Eds.), Proceedings of the Second Goal Attainment Scaling Conference. Minneapolis: Program Evaluation Resource Center, 1974, 111-124.

Bandura, Albert. Principles of Behavior Modification. New York: Holt, Rinehart and Winston, 1969.

Bolin, David C. and Kivens, LAWrence. Evaluating a community mental health center: Huntsville, Alabama. Evaluation, 1,3, $1973,17-18$

Charters, W. W. and Jones, JohN E. On the risk of appraising non-events in program evaluation. Educational Researcher, 1973, November, 5-7.

DAvIS, Howard. Four ways to goal attainment. Evaluation, 1,2, $1973,43-48$

Davis, Howard. Change technology and goal-oriented evaluation. In Geoffrey Garwick and Joan Brintnall (Eds.), Proceedings of the Second Goal Attainment Scaling Conference. Minneapolis: Program Evaluation Resource Center, 1974, 1-24.

Doyle, Kathleen M. and Levy, Stephen J. The female client; How treated in drug abuse programs. Paper presented at the Annual Meetings of the American Psychological Association, 1975.

Edwards, Ward, Guttentag, Marcia, and Snapper, Kurt. A decision-theoretic approach to evaluation research. In E. L. Struening and M. Guttentag (Eds.), Handbook of Evaluation Research. Beverly Hills: Sage, 1975, 139-182.

Etzioni, Amitai. Two approaches to organizational analysis: A critique and a suggestion. Administrative Sciences Quarterly, $1960,5,257-278$

HLuChJy, TerRy. Human service or social movement: Organizational considerations in a drug treatment program for women. WOMAN Center Evaluation, Year 2: A report to NIDA. Unpublished report, The University of Michigan, 1976.

Houts, Peter S. and Scott, Robert A. Goal Planning in Mental Health Rehabilitation. Department of Behavioral Science, The Pennsylvania State University, 1972.

Kiresuk, Thomas J. Basic goal attainment scaling procedures. Chapter One, Program Evaluation Project Report, 1969-1973. Minneapolis: Program Evaluation Resource Center, 1974.
Kiresur, Thomas J. and Sherman, Robert E. Goal attainment scaling: A general method for evaluating comprehensive community mental health programs. Community Mental Health Journal, 1968, 4, 443-453.

Mager, Robert. Goal Analysis. Belmont, Ca.: Fearon, 1972.

Miller, Gary. A variant of goal attainment scaling: ProGAST. Evaluation, 1,3, 1973, 17-18.

Raia, Anthony P. Managing by Objectives. Glenview, Illinois: Scntt Foresman, 1974

ReID, William J. and Epstein, Laura. Task-Centered Casework. New York: Columbia University Press, 1972.

Riecken, Henry W., Boruch, Robert F., Campbell, Donald T., Caplan, Nathan, Glennan, Thomas K., Pratt, John W., Rees, Albert, Williams, Walter. Social Experimentation: A Method for Planning and Evaluating Social Intervention. New York: Academic Press, 1974.

Rosenthal, Barry J., Spillane, William H., and Greene, Bradrord T. Treatment outcome: Is sex a factor. Paper presented at the National Drug Abuse Conference, 1976.

Rossi, Peter H. Testing for success and failure in social action. In P. Rossi and W. Williams (Eds.), Evaluating Social Programs. New York: Seminar, 1972.

Salasin, S. Exploring goal-free evaluation: An interview with Michael Scriven. Evaluation, 1974, 2, 9-16.

Schulberg, Herbert C. and Baker, Frank. Program evaluation models and implementation of research findings. American Journal of Public Health, 1968, 58, 1248-1255.

Suchman, Edward A. Evaluation Research: Principles and Practice in Public Service and Social Action Programs. New York: Russell Sage Foundation, 1967.

Tripodi, Tony, Fellin, Phillip and Epstein, Irwin. Social Program Evaluation: Guidelines for Health, Education and Welfare Administrators. Ithasca, Illinois: Peacock, 1971.

Weiss, Carol H. Evaluation Research. Englewood Cliffs: Prentice-Hall, 1972.

Zander, Alvin. Motives and Goals in Groups. New York: Academic Press, 1971

\section{Footnotes}

\begin{abstract}
${ }^{1}$ Etzioni has described one of the functions of formal or public goals to be that of recruiting support (inputs) to the organization from groups that would not support the private goals. The goals
\end{abstract}

determined by the WOMAN Center were those most relevant to the source of funding, the National Institute of Drug Abuse. 